\title{
Análise sobre a Dimensão Oferta no Contexto Inovação dentro do Setor de Estruturas Pré-moldadas na Grande Natal ${ }^{1}$
}

\section{Analysis About Offer Dimension in the Context Innovation Inside of Sector Precast Structure in Natal}

\author{
Marcela C. Campos Capeleiro \\ Endereço: Rua Professor Adolfo Ramires, Quadra 10, Bloco G,Apt ${ }^{\mathrm{o}}$ 101, Capim Macio \\ CEP: 59078-460 - Natal / RN \\ Instituição: Agente Local de Inovação SEBRAE/ Bolsista CNPQ \\ Telefone para contato: (84) 9657-4786 / (84) 3207-6753 \\ Richard Medeiros de Araújo \\ Endereço: Rua Rio Paranapanema, 7933, Cidade Satélite - CEP: 59068-330 - Natal/RN \\ Instituição: Professor do UNIFACEX e Orientador do ALI/RN - SEBRAE - CNPQ \\ Telefone para contato: (84) 8702-4034
}

\section{RESUMO}

Este trabalho busca investigar, através de uma abordagem qualitativa, as práticas de inovação das micro e pequenas empresas do setor de estruturas pré-moldadas na região da Grande Natal, RN, utilizando as dimensões conceituais do Radar da Inovação aplicadas a essas empresas. Por meio dessas dimensões avaliou-se o grau de inovação presente nelas. Dentre as dez dimensões abordadas pelo Radar, se encontra a dimensão Oferta, que faz referência à inovação dos produtos oferecidos pela empresa ao mercado. Para elaboração da análise, foi previamente elaborada uma discussão teórica sobre os conceitos de inovação, sustentabilidade e o atual cenário nacional do setor de estruturas pré-moldadas. Em seguida, foi elaborada uma pesquisa qualitativa-exploratória com quatro empresas do segmento estudado que são atendidas pelo programa Agentes Locais de Inovação do Rio Grande do Norte. Com a aplicação da pesquisa foi possível perceber que há um campo amplo de inovação a ser trabalhado nessas empresas, tendo em vista que foi observado que as estas não possuem a cultura da inovação, inovam apenas por necessidade. Também foi percebido o abismo existente entre Instituições de Ensino Superior e empresas privadas. Conclui-se que os empresários possuem conceitos amplos sobre inovação, o que facilita o incentivo à cultura da inovação, seja por parte do governo, instituições de ensino ou empresas privadas.

Palavras-chave: Inovação. Oferta. Estruturas pré-moldadas. Radar da Inovação.

\section{ABSTRACT}

This paper aims to investigate, through a qualitative approach, the innovation practices of micro and small enterprises in precast structures in the region of Natal, RN, using the conceptual dimension of Radar Innovation applied to these companies. Through these dimensions evaluated the degree of innovation of enterprises. Among the ten dimensions broached by radar, there is offer dimension, which refers to the innovation of products offered by the company to the market. For elaboration of the analysis, was previously developed a theoretical discussion of the concepts of innovation, sustainability and

\footnotetext{
1 Artigo recebido em 27.02.2013. Revisado pelos pares em 19.04.2013. Reformulado em 03.05.2013. Aceito para publicação em 10.06.2013. Recomendado para publicação por José Ribamar Marques de Carvalho (Editor Científico). Publicado em 17.07.2013. Organização responsável UACC/UFCG.
} 
the current national scenario sector precast structures. Next was achieved a research exploratory qualitative with four companies of segment, that are served by the program Agentes Locais de Inovação of Rio Grande do Norte. With the application of the research was possible to see that there is a broad field of innovation can be worked in these firms, given that it was observed that they do not have a culture of innovation, innovate only by necessity. Also noticed was the gap between higher education institutions and private companies. We conclude that entrepreneurs possess broad concepts about innovation, which facilitates the stimulation of innovation culture, whether by government, educational institutions or private companies.

Keywords: Innovation. Offer. Precast structures. Innovation Radar.

\section{INTRODUÇÃO}

Dada a importância socioeconômica das Micro e Pequenas Empresas (MPE's) no país, tendo em vista que estas representam $93 \%$ do universo total de empresas formalizadas no Brasil, sendo responsáveis pelas maiores taxas de empregabilidade e geração de renda (ALMEIDA, 2012), faz-se necessário aprofundar o conhecimento da realidade destas organizações, tanto para desenvolver políticas públicas mais apropriadas, quanto para oferecer serviços privados que venham a contribuir para o desenvolvimento delas.

No Brasil, onde a taxa de mortalidade das empresas nos primeiros quatro anos é elevada, há uma preocupação por parte do governo em fomentar a inovação como um diferencial competitivo. O SEBRAE, neste ponto, torna-se um dos maiores parceiros do governo, oferecendo aos micro e pequenos empresários suporte nas mais diversas áreas, com cursos, consultorias, orientações e programas específicos para a inovação, como o Programa Agentes Locais de Inovação (DORNELAS, 2008). No entanto, para se trabalhar a inovação, faz-se necessário previamente conhecer o universo das MPE's e entender até que ponto elas estão suscetíveis à inovação. Para isso, segundo Bachmann e Destefani (2008), uma das ferramentas aplicadas é o Radar da Inovação que gera indicadores, como o grau de inovação, por exemplo. Esses indicadores permitem ir além do grau de inovação, com eles também é possível avaliar a eficácia do processo de inovação. No Brasil, por exemplo, existem 0,018 patentes por milhão de dólar investido em P\&D (BACHMANN; DESTEFANI, 2008), ou seja, um número relativamente baixo para o valor investido. Este dado sugere que pode existir uma falha no processo que vai desde o empresário querer inovar, pesquisar, desenvolver e até patentear e comercializar. Desta forma, descobrir quais são essas barreiras empresariais ou culturais é fundamental para o desenvolvimento de ações que estimulem a inovação e o crescimento das MPE's, no Brasil.

O Radar da Inovação, desenvolvido pela empresa Bachmann\&Associados em parceria com o SEBRAE, objetiva quantificar o grau de inovação das empresas segundo alguns critérios subdivididos por dez dimensões. São elas: Oferta, Marca, Clientes, Soluções, Relacionamento, Agregação de Valor, Processos, Organização, 
Cadeia de Fornecimento, Rede e Ambiência Inovadora. A dimensão a ser trabalhada neste paper é a Oferta, a qual abrange oito perguntas relacionadas a novos mercados, novos produtos, ousadia, resposta ao meio ambiente, design, inovação tecnológica, sistema de produção e versões de produtos. O instrumento de análise consiste em uma pontuação que vai de 1 a 5 , entendendo-se que quando a empresa possui pontuação 1, significa que tem baixo nível de inovação. Já quando o radar apresenta nível 5, entende-se que a empresa possui alto nível de inovação. Seguindo esta pontuação é possível avaliar o grau de inovação no primeiro momento (primeira aplicação do instrumento no início do projeto) e no segundo momento (segunda aplicação no término do projeto), fazendo uma comparação e medindo a evolução da inovação na empresa após a passagem pelo Programa Agentes Locais de Inovação (ALI) (BACHMANN, 2011).

A globalização e as rápidas mudanças tecnológicas são fatores essenciais de mudança no cenário socioeconômico, transformando a natureza e as condições do desenvolvimento local (DINIZ, 2011). Para que as empresas continuem se mantendo competitivas no mercado frente a estas mudanças, elas precisam estar sempre em processo de melhoria e atualização. Nesse sentido, a inovação se torna algo essencial na vida de qualquer empresa, seja ela grande, média, pequena ou micro.

Tendo em vista estes aspectos, este paper objetiva fazer uma análise entre a dimensão Oferta da ferramenta do Radar da Inovação e as reais práticas das empresas do setor de pré-moldados em Parnamirim, evidenciando o cenário mercadológico atual e as novas tendências para o setor. Procurou-se também o comportamento inovador dos dirigentes das empresas perante o uso de novos materiais ecológicos, assim como o uso da sustentabilidade como ação promocional. Tendo como objetivo geral investigar as práticas inovadoras no universo das MPE's do setor de pré-moldados na Grande Natal utilizando como parâmetro a ferramenta Radar da Inovação e objetivos secundários descrever o uso de processos ou materiais ecológicos na produção de estruturas pré-moldadas como um diferencial competitivo; investigar a aceitação da inovação como fator de sobrevivência da empresa por parte dos empresários.

\section{REFERENCIAL TEÓRICO}

\subsection{Inovação}

Falar de inovação hoje em dia, de acordo com Bessant e Tidd (2009) já é algo comum. Não é preciso procurar muito para perceber a necessidade da inovação. Ela está presente em diversas missões empresariais e até mesmo em diferentes anúncios de produtos, “[...] desde sprays para cabelos até de serviços para a saúde. É presença 
marcante no coração de nossos livros de história, mostrando até que ponto e por quanto tempo influencia nossas vidas" (BESSANT; TIDD, 2007, p.20). Entretanto, apesar de ser um tema empiricamente comum, ainda segundo Bessant e Tidd (2009), este é um assunto relativamente novo no meio acadêmico brasileiro, sendo ainda pouco explorado pelas empresas. Apesar disto, todos reconhecem seu importante papel para o desenvolvimento da economia, tornando as empresas mais competitivas e melhorando, cada vez mais, os produtos e serviços que chegam ao consumidor (BES; KLOTER, 2011).

A inovação é um elemento que faz diferença para as empresas de todos os tipos e portes. Isso porque, simplesmente, se a empresa não mudar o que oferece ao mundo (bens e serviços) e como oferece, ou seja, processo de produção, oferta, etc., corre o risco de ficar para trás, pois outros certamente o farão. De uma forma bem clara, inovação é uma questão de sobrevivência no mercado (BESSANT; TIDD, 2009).

Esta importância para as empresas se deve ao fato de a inovação ser, segundo Terra (2007), uma ferramenta que permite aos empreendedores explorar as mudanças como possíveis oportunidades de mercado. Entretanto, a inovação não está restrita ao meio empresarial, mas presente no quotidiano das pessoas. A palavra "inovar" deriva do latim in+novare, que significa "fazer novo", renovar ou alterar. Deste modo, inovação significa criar algo novo, ou melhorar o antigo (TERRA, 2007).

Vale ressaltar que quando se fala em "criar" não se pode confundir inovação com invenção. Para efeito de conhecimento, a diferença entre os dois conceitos está no fator de implementação e de propagação das ideias. Ou seja, não basta ter uma ideia para que seja inovação, é preciso haver aceitação por parte da sociedade, caso contrário, será apenas mais uma invenção.

Sendo assim, existem dois tipos de inovação: a incremental e a radical. No caso, a incremental é justamente aperfeiçoar um produto, serviço ou conceito já existente. Já a radical, como o nome diz, é fazer algo completamente novo, diferente de tudo o que já existe (BESSANT; TIDD, 2009). De acordo com Turetta (2012), pequenas mudanças no processo produtivo (inovações incrementais) fazem grande diferença no resultado final do produto e no desempenho financeiro, sendo tão importantes como a radical.

Contudo, é importante ressaltar que a necessidade de inovar deve andar em paralelo com a cultura de inovação. Isso, porque segundo Bes e Kloter (2011), ainda não há uma cultura de inovação nos brasileiros. O Brasil é um país inovador, o problema é que uma grande percentagem dos empreendedores inova por necessidade e não por considerarem isto algo crucial e constante para a empresa. Ainda há no brasileiro o pensamento de que inovação necessita ser algo novo e que envolva tecnologia de ponta e altos investimentos. Quando na verdade, a inovação sustentável é aquela gradual, que é feita passo a passo (TERRA, 2012). Cada setor 
deve ser responsável e dar sua contribuição para que o todo funcione, desde a Pesquisa e Desenvolvimento (P\&D) aos Recursos Humanos (RH). A empresa deve desenvolver o hábito de inovação para poder se manter competitiva no mercado (BES; KLOTER, 2011). Dessa forma:

[...] a solução não é pensar na criação de uma inovação radical hoje, mas pensar em sua ocorrência como um conjunto de pequenos passos inovadores ao longo do tempo, culminando em uma inovação significativa (BES E KOTLER, 2011, p.19).

Observa-se também que as empresas têm um potencial de inovação em fontes internas. O problema é que muita destas não o aproveita, ou pelo menos não da forma correta. É comum o pensamento errôneo de que apenas alguns setores são responsáveis pela inovação, como a pesquisa e desenvolvimento (P\&D) e o Marketing, por exemplo. A tecnologia é importante neste processo, porém, “(...) se não for integrada com a criação e a captação de valor, não atenderá às necessidades do cliente e, assim, fracassará." (BES; KOTLER, 2011, p.17).

Além disso, o fato de muitos confundirem inovação com criatividade, a falta de coordenação de projetos e a falta de foco no cliente também são barreiras consideráveis à inovação empresarial (BES; KOTLER, 2011). Uma das formas de quebrar estas barreiras é estimular e desenvolver o conhecimento dentro das organizações. Para isto, segundo Terra (2007), o compartilhamento do conhecimento é de suma importância. Hoje em dia, na chamada "Era do Conhecimento", em que as informações chegam cada vez mais rápido, é necessário criar métodos para produção e organização de conhecimentos (TERRA, 2007).

Nesse ponto, a Gestão do Conhecimento deixa de ser apenas uma disciplina de cursos de Pós-graduação e passa a ser peça fundamental em qualquer empresa que busque inovar e se tornar competitiva no marcado. Terra (2007) também esclarece que a produção de novos conhecimentos não é algo instantâneo, leva tempo e depende de vários fatores, como experiências, motivação para aprender, características da inteligência de cada indivíduo, etc. Entretanto, existem técnicas que podem auxiliar na produção do conhecimento, como: estabelecer desafios de aprendizado; foco no talento e na diversidade; parar a linha de produção; incentivar contatos diretos com os clientes; flexibilizar o ambiente de trabalho; prover experiências; celebrar inovação (TERRA, 2007).

Outro aspecto importante que deve ser analisado na cultura da inovação são as parcerias desenvolvidas entre empresas. Como já foi citado, o compartilhamento de informações é um grande estímulo à inovação e esta troca não se restringe ao ambiente interno da empresa, mas também ao externo (ZAGO et al., 2007). Neste 
ponto de vista, a união entre empresas lhes permite aperfeiçoar vários aspectos, não só organizacionais, mas também em pesquisa e desenvolvimento (P\&D), logística, diversificação de oferta, compra de insumos, ou apenas para trocarem informações sobre o mercado (ZAGO et al., 2007). Estas associações permitem às médias, pequenas e micro empresas fazerem frente aos grandes empreendimentos multinacionais, à globalização e as rápidas mudanças tecnológicas. Afinal,

"A cooperação oferece a possibilidade de as empresas disporem de tecnologias e reduzirem os custos relativos ao processo de inovação, aumentando a eficiência econômica e, por consequência, a competitividade" (MORRIS-SUZUKI, 1980, p.58 apud ZAGO et al., 2007).

Com as parcerias, não só as empresas tem saldo positivo, mas também o consumidor, que terá um produto/serviço de maior qualidade e melhor preço. Assim, percebe-se como é importante a parceria empresarial para desenvolvimento socioeconômico de um setor ou localidade (ZAGO et al., 2007).

Nesse contexto da necessidade de inovar como uma constante, as organizações devem se colocar como agentes propulsoras do processo de autossustentação de suas respectivas vantagens competitivas. A inovação é um mecanismo que não só pode ser concebido, como uma atividade empresarial, como deve compor um portfólio de estratégias. Tal encaminhamento apregoado de intervenções no modelo de gestão devem convergir com os interesses dos consumidores e demais atores que estejam envolvidos.

\subsection{Inovação e Sustentabilidade}

Ao falar sobre inovação torna-se inevitável não abordar a sustentabilidade. Pois através de ações inovadoras as empresas trilham caminhos cada vez mais sustentáveis. Entretanto, muitos ainda não correlacionam um tema com o outro. Muito se fala em inovação, mas pouco nos dois conceitos juntos. Segundo Almeida (2012), apesar do rápido crescimento no número de MPE's no país, muitas empresas ainda dão passos lentos quando o assunto é inovação e sustentabilidade. “[...] as inovações relacionadas à gestão ambiental são apenas o início de uma mudança de postura que envolve a estratégia competitiva e tendência do mercado [...]" (ALMEIDA, 2012, p.299).

A inovação pode e deve ser uma solução para reduzir custos e tornar a empresa mais sustentável (SOUSA; CARVALHO, 2012). Para se adentrar neste campo, é preciso antes esclarecer o que é desenvolvimento sustentável. Segundo Sousa e Carvalho (2012), o desenvolvimento sustentável apresenta pontos básicos que devem considerar o crescimento econômico, maior percepção dos resultados sociais decorrentes e o equilíbrio ecológico na utilização de recursos naturais. Além 
disso, a empresa precisa ser financeiramente viável, economicamente justa e socialmente aceitável. Este conjunto caracteriza o desenvolvimento sustentável. Neste contexto, as autoras Sousa e Carvalho (2012) afirmam que a inovação tem sido um instrumento, cada vez mais, utilizado para ocasionar práticas sustentáveis nas organizações.

No entanto, segundo Bessant e Tidd (2009), a inovação é, geralmente, tida como algo antagônico à sustentabilidade. Isso porque, muitas vezes, ela está associada ao desenvolvimento tecnológico que consome os recursos da sociedade. Apesar deste errôneo conceito, a inovação possui um papel fundamental em ajudar a criar futuros sustentáveis, através de: processos mais eficientes - para minimizar ou tratar resíduos; produtos mais limpos - com impacto ambiental menor ao longo de seu ciclo de vida; tecnologias alternativas - para reduzir as emissões, fornecer energia renovável; novos serviços - para substituir ou reduzir o consumo de produtos; inovação sistêmica - para mensurar e monitorar o impacto ambiental; promoção de mudanças organizacionais - introduzir a cultura da inovação como um fator essencial ao desenvolvimento (BESSANT; TIDD, 2009).

Bessant e Tidd (2009) afirmam ainda que, muitas vezes, a inovação sustentável tem sua origem em nichos de mercado e que esses nichos podem amadurecer e crescer para influenciar a demanda e o desenvolvimento do mercado dominante. Além disso, a inovação depende ainda da aceitação/adoção por parte da sociedade. Para isso, depende também da comunicação. Modelos epidêmicos partem do princípio que inovação se difunde por meio de comunicação entre os adotantes. Entretanto, muitas vezes, a linha pode ser inversa e a população passa a influenciar a inovação, é o caso dos usuários líderes. Estes são “[...] fundamentais para o desenvolvimento e a adoção de novos nichos e inovação sistêmica" (BESSANT; TIDD, 2009, p. 372).

Dessa forma, é perceptível os dois olhares diferentes entre os autores sobre o conceito de sustentabilidade e inovação. Para Carvalho (2012) a sustentabilidade é um conjunto de características que devem ser levadas em consideração para inovar e se posicionar. Já Bessant e Tidd (2009) acreditam que a sustentabilidade é uma consequência da inovação que vem em decorrência de soluções para problemas existentes.

Independente se as ações sustentáveis são consequência da inovação ou não, percebe-se que com uma melhor compreensão das dinâmicas da inovação, incluindo o desenvolvimento, a adoção e a difusão da mesma, uma trajetória mais sustentável pode ser explorada. Afinal, "o processo de inovação é muito mais complexo que a resposta tecnológica a sinais mercadológicos" (BESSANT; TIDD, 2009, p.392).

\subsection{Cenário Atual da Construção Civil e Estruturas Pré-Moldadas}


Ao entrar no campo de pré-moldados é necessário antes analisar o setor da construção civil como um todo, tendo em vista que estão diretamente relacionados. Com o crescimento econômico e populacional, o setor da construção civil está em crescente expansão, com crescimento de 4,8\% em 2011, segundo a Câmara Brasileira da Indústria de Construção (CBIC, 2012).

Essa cadeia produtiva representa um importante papel na economia e no desenvolvimento social (PEREIRA 2008). Nos últimos anos, o governo do Brasil tem investido bastante na habitação popular, o que impulsiona ainda mais o setor e gera desenvolvimento social. Segundo a Associação Brasileira de Cimento Portland ABCP, entre 2010 e 2024, o Brasil deverá construir mais de 23 milhões de novas moradias para atender este crescimento populacional, reduzir o déficit habitacional e eliminar as moradias precárias. Para atender esta demanda crescente, a indústria da construção civil precisa investir em novas tecnologias que tornem o processo produtivo mais limpo, barato e rápido.

Entretanto, Pereira (2008) ressalta que o ramo da construção civil nacional sente dificuldade em inovar. Ainda segundo a $\mathrm{ABCP}$, parte disto se dá pelo complexo processo de produção, que envolve diversos agentes e processos burocráticos. Para Pereira (2008), outro fator que contribui para o lento desenvolvimento da inovação no setor é o fato de o mesmo absorver muita mão de obra não qualificada. Esse atraso também é caracterizado pela base manufatureira, o baixo grau de mecanização, o desperdício de materiais de construção, a não padronização do produto, a preocupação com o custo acima da qualidade, entre outros (CASTRO, 1999 apud PEREIRA, 2008).

Esse cenário tem se modificado aos poucos à medida que vem sendo desenvolvidos, cada vez mais, estudos sobre construções eficientes e processos produtivos sustentáveis. Isso deriva da carência habitacional e de fracassos em programas governamentais, o que direcionou a produção acadêmica a se concentrar na crítica à indústria da construção civil e à política habitacional, focando na tecnologia como a chave da produtividade e do barateamento da construção (MASCARÓ, 1992 apud PEREIRA, 2008).

Pereira (2008) também afirma que as empresas que investem em Pesquisa e Desenvolvimento, a fim de desenvolverem inovação tecnológica e processual, conseguem se tornar mais competitivas no mercado e contribuem para $\mathrm{O}$ desenvolvimento do setor como um todo.

Hoje em dia, o mercado busca prazos cada vez menores e qualidade cada vez maior, fatores que vêm forçando a construção civil a embarcar em novos desafios em busca de tecnologias diferenciadas, nos diversos setores (IGLESIA, 2006). Observa-se então a "industrialização" desse setor através do uso de peças de concreto pré- 
moldadas, já que estas se caracterizam pela sua facilidade e rapidez de aplicação (SERRA, 2004 apud IGLESIA, 2006). Esse panorama não está restrito ao Brasil, ele pode ser percebido em diversos países. No norte da Europa, por exemplo, a maioria das construções é feita com estruturas externas pré-moldadas (IGLESIA, 2006). As vantagens destas estruturas de concreto se caracterizam, principalmente, pela resistência ao fogo, isolamento acústico, rapidez na obra e acabamento liso.

As estruturas pré-moldadas também assumem um papel fundamental no passo à sustentabilidade da construção civil. Já que segundo a $\mathrm{ABCP}$, nos últimos anos, a sociedade vem adquirindo - cada vez mais - consciência sobre o impacto ambiental causado pela construção e vem atribuindo ainda mais importância na pesquisa, desenvolvimento e utilização de materiais menos agressivos ao meio ambiente. O concreto, matéria-prima das estruturas pré-moldadas, se adequa a estas novas exigências sustentáveis, já que possui equilíbrio por meio de suas matériasprimas, processos de produção e impactos na infraestrutura e ambiente construído. Efetivamente, o concreto não gera emissões, não requer conservantes tóxicos e apresenta uma inerente resistência ao fogo, consumindo menos energia na sua produção em comparação com a maioria dos demais insumos de construção ( $\mathrm{ABCP}$, 2012).

Além disso, outra inovação já começou a ser utilizada no Brasil para reduzir o impacto ambiental do concreto: o coprocessamento. Esse é um processo de destruição de resíduos e de passivos ambientais em fornos de cimento. $\mathrm{O}$ coprocessamento usa resíduos em substituição parcial ao combustível que alimenta a chama do forno que transforma calcário e argila em clínquer, matéria-prima do cimento. Esta técnica já é amplamente utilizada há vários anos em lugares como os Estados Unidos, Japão e vários países da Europa (ABCP, 2012).

Essas características do pré-moldado, como sua resistência, segurança, agilidade da obra e o baixo impacto ambiental são pouco exploradas pelos fabricantes como estratégias de marketing e vendas. Assim, é possível perceber a importância do setor de pré-moldados para o desenvolvimento da construção civil e da sociedade como um todo. O mercado está em expansão e é de suma importância que as empresas busquem na inovação um diferencial competitivo.

\subsection{Radar da Inovação e a Dimensão Oferta}

Segundo Bachmann e Destefani (2008), o processo de inovação inclui atividades de diversas etapas científicas, tecnológicas, organizacionais, financeiras e comerciais. Essas etapas levam à implementação ou melhoria de produtos, serviços e processos novos ou melhorados. Ao longo dos anos, o processo de inovação evoluiu de técnicas rudimentares para práticas complexas e sofisticadas (BACHMANN; 
DESTEFANI, 2008). Já que, de acordo com esses mesmo autores, o processo de inovação conta com duas extensões, a física e a intangível. A física aborda estruturas organizacionais, que favorecem a inovação e a intangível aborda liberdade de comunicação, cultura de aceitação de riscos, práticas de técnicas de criatividade, entre outros.

Com base nessas extensões, foi criado um formulário para operacionalizar o cálculo do Grau de Inovação: o Radar da Inovação, dentro do Radar encontram-se dez dimensões: Oferta, Marca, Clientes, Soluções, Relacionamento, Agregação de Valor, Processos, Organização, Cadeia de Fornecimento, Rede e Ambiência Inovadora (BACHMANN; DESTEFANI, 2008). Nesse artigo será analisada a dimensão Oferta, fazendo-se uma discussão aprofundada. A Oferta pode ser definida como os produtos oferecidos pela empresa ao mercado. De acordo com o conceito de que uma empresa inovadora tem uma parte relevante de sua receita associada a novos produtos, e como o conceito que associa a inovação inclui à disposição para correr riscos, o instrumento inclui as seguintes questões:

- "A empresa lançou, com sucesso, algum novo produto no mercado nos últimos 3 anos?"

- "A empresa lançou, nos últimos 3 anos, algum produto que não deu certo?".

Com a rápida evolução das mudanças comportamentais do consumidor, que estão cada vez mais exigentes, principalmente no quesito sustentabilidade, o questionário inclui a pergunta:

- “A empresa modificou, nos últimos 3 anos, alguma característica de seus produtos por razões ambientais (ecológicas)?"

A comunicação faz-se, cada vez mais, necessária para atingir o público-alvo, dentro dela encontra-se o design, não só da embalagem, mas como do produto em si. Para avaliar este quesito, temos a seguinte questão:

- "A empresa fez alguma mudança significativa na estética, desenho ou outra mudança subjetiva em seus produtos?"

Para ter seus produtos ou serviços competitivos no mercado, a empresa precisa sempre inovar, comprar equipamentos, melhorar os processos produtivos ou criar várias versões do produto/serviço. Para poder avaliar estes aspectos, o questionário inclui a seguinte pergunta:

- "A empresa adotou alguma das seguintes inovações: uso de novos materiais; uso de novos produtos/ serviços intermediários; uso de novas peças funcionais; uso de tecnologia radicalmente nova?"

Com estas cinco perguntas é possível avaliar o grau de inovação da empresa, no segmento industrial, dentro da dimensão Oferta (BACHMANN; DESTEFANI, 2008). 
Entretanto, precisa-se compreender previamente o conceito de oferta segundo a economia, para assim poder fazer uma análise do instrumento - Radar da Inovação - que utiliza sete variáveis para descrever a dimensão Oferta.

Desta forma, segundo Paiva e Cunha (2008), a teoria de oferta é mais complicada que a teoria de demanda e as duas estão interligadas. Uma vez que os agentes demandantes são indivíduos consumidores, e os agentes ofertantes são empresas capitalistas. Para estes autores, o objetivo do consumidor é adquirir e consumir valores, de forma a potencializar sua satisfação, ao longo da vida. Já os objetivos das empresas é acumular lucros. Pode-se assim dizer que o desejo do consumidor será ofertado pela empresa, ou seja, o consumidor gera demanda e a empresa a oferta.

Já segundo Bergo (2011), pode-se definir oferta como um conjunto de diversas quantidades que os produtores estão dispostos a oferecer ao mercado, em dado período de tempo. Nesse contexto, a análise da oferta busca explicar o comportamento do empresário, caracterizado por um sujeito interessado em produzir e ofertar um determinado produto ou serviço. Voltando ao conceito de Paiva e Cunha (2008), a oferta será determinada pelas variáveis da demanda, que são constituídas por: preço, concorrência, custos de produção, tecnologia, entre outros. Através dos conceitos explanados durante o capítulo de Referencial Teórico, é possível conhecer e entender o cenário atual da inovação e do setor de estruturas prémoldadas. Esse conhecimento auxiliará o leitor e autor na compreensão das análises e discussões da pesquisa.

\section{PROCEDIMENTOS METODOLÓGICOS}

A fim de atingir os objetivos deste artigo, que se caracterizam em investigar as práticas inovadoras das MPE's do setor de pré-moldados na Grande Natal utilizando como parâmetro a ferramenta Radar da Inovação, realizou-se uma pesquisa exploratória/descritiva. Segundo Aaker et al. (2010), a pesquisa exploratória deve ser utilizada quando se tem pouco conhecimento inicial sobre o tema e pretende-se buscar um entendimento sobre a natureza geral de um problema. Os métodos utilizados nesse tipo de pesquisa são flexíveis e têm caráter qualitativo. Desta forma, foram utilizados roteiros de entrevista, pesquisas em campo e estudos bibliográficos. Esta pesquisa também terá o caráter descritivo com abordagem qualitativa, já que busca descrever o fenômeno investigado de forma a obter dados até então especulativos. De acordo com Aaker et al. (2010), a pesquisa descritiva é utilizada quando existem hipóteses que frequentemente não passam de especulações.

O universo desta pesquisa contempla quatro empresas de estruturas prémoldadas situadas nas cidades de Parnamirim, Natal e Macaíba, todas localizadas no 
Rio Grande do Norte atendidas pelo Programa Agentes Locais de Inovação, que aqui estão denominadas de empresa $A$, empresa $B$, empresa $C$ e empresa $D$, na pessoa do gestor de cada uma (considerando os proprietários das empresas A, B e C e o gerente da D). Para esta pesquisa foi utilizada a técnica amostral não probabilística por conveniência. Esta técnica é utilizada quando se deseja obter informações de forma rápida sobre um conceito preliminar, geralmente de um grupo já definido (AAKER et al., 2010).

Como instrumento de pesquisa, foi utilizado o Radar da Inovação, contemplando apenas a dimensão Oferta com suas cinco perguntas que buscam investigar quatro variáveis, que são: lançamento de novos produtos, sustentabilidade, design e melhoria de processos produtivos/inovação tecnológica. Entretanto, sentiu-se a necessidade de utilizar um roteiro de entrevista complementar a fim de obter mais dados qualitativos que auxiliem na análise das variáveis. Com isto, foi utilizada a técnica de entrevista semiestruturada, pois segundo Aaker et al. (2010), a estrutura aberta proporciona ao entrevistador oportunidade para explorar fatos inesperados. Ainda segundo o autor, neste tipo de entrevista o pesquisador procura explorar uma lista específica de assuntos relacionados ao tema investigado.

O roteiro de entrevista semiestruturado foi constituído de sete perguntas abertas que buscam avaliar as variáveis de novos produtos, busca de novas tecnologias, conhecimento científico, qualificação de mão de obra e sustentabilidade, que emergiram a partir dos autores Bachmann e Destefani (2008), Bergo (2011) e Bessant e Tidd (2007).

No que se refere à análise dos dados, pode-se confirmar que tanto nos dados coletados com a aplicação do Radar da Inovação quanto nos do roteiro de entrevista, tem-se as falas dos Sujeitos e suas percepções sobre as variáveis as quais foram expostos. Para proceder tal análise, optou-se pela análise de conteúdo que é uma técnica de observação utilizada para analisar dados coletados por meio escrito (AAKER et al., 2010).

Devido ao caráter qualitativo da pesquisa, a análise e a interpretação dos dados é mais complexa e divergente do que de uma pesquisa quantitativa. Isso porque cada analista pode encontrar algo que seja coerente com seu ponto de vista, com seu objetivo e problema (AAKER et al, 2010). Para poder preparar os dados para análise, foi utilizada a técnica de edição. Segundo Aaker et al (2010), a edição consiste em identificar omissões, ambiguidades e erros nas respostas. Após a edição, constatou-se que não seria necessário retorno e novas entrevistas, tendo em vista que os empresários foram coerentes em suas respostas e de uma forma geral responderam as perguntas claramente. 


\section{ANÁLISE E DISCUSSÃO DOS DADOS}

Considerando que a pesquisa tem um caráter qualitativo, os dados do Radar da Inovação serão dispostos neste capítulo junto com a apresentação das falas dos Sujeitos que representam as empresas A, B, C e D. Dessa forma, será apresentada uma discussão detalhada entre as pontuações de cada variável da dimensão Oferta do Radar da Inovação e as respostas obtidas no roteiro de entrevista, fazendo um parâmetro entre a teoria e a prática. As análises também serão dispostas em dois subitens, o primeiro consiste em uma análise resumida da pontuação obtida pelas quatro empresas em todas as dimensões do Radar da Inovação e a segunda focando apenas na dimensão Oferta, objeto de estudo deste paper.

\subsection{Caracterização das Empresas}

A Empresa A fica localizada na cidade de Parnamirim e tem como faturamento médio anual $\mathrm{R} \$ 360.000,00$, constituindo-se como microempresa (ME). O foco desta empresa é a produção de vigas, lajes, várias categorias de pisos, cobogó, etc. O empresário (vamos chamá-lo aqui por Sujeito A) tem 34 anos e faz faculdade de Engenharia Civil. Ele elabora todas as suas formulações e afirma ter desenvolvido um produto inovador que posteriormente foi copiado por vários outros prémoldados da região. Para ele, inovação é criar algo novo ou melhorar aspectos da fabricação que tornem o produto melhor e mais sustentável, como fica evidenciado em sua fala: "[...] sempre vejo como criar, inventar, engenhar novos aspectos de fabricação. Eu sempre gosto de mudar, quando eu vejo que não tá fabricando do jeito bom, eu tento mudar a maneira de fabricar [...] é criar novas possibilidades [...] que ajudem principalmente o meio ambiente [...] (Sujeito A, 2012).

A Empresa B também fica situada em Parnamirim e também se classifica como microempresa. Seus produtos são semelhantes aos da empresa A. O empresário (Sujeito B) por sua vez, cursou apenas o Ensino Médio. Tem 37 anos e deseja no futuro fazer cursos para seu aperfeiçoamento intelectual, mas no momento alega falta de tempo para tal. As formulações dos produtos são feitas por técnicos conhecidos ou adquiridas com outros pré-moldados parceiros. Para ele, inovar é lançar novos produtos com os quais ele antes não trabalhava, seja ideia sua ou de outros. Além disso, inovar para ele também é melhorar seus processos em nível de estrutura, como fica evidente em sua fala: "Inovação é melhorar tanto na área do produto para o cliente e inovar-nos outros aspectos também" (Sujeito B, 2012).

A empresa C, fica localizada em Natal e também é uma ME. O empresário (Sujeito C), de 52 anos fez o curso técnico de geologia e trabalhou muitos anos na Petrobrás. Abriu, inicialmente, uma loja de materiais de construção e, 
posteriormente, optou por fabricar peças pré-moldadas. No entanto, ele se concentra apenas em vigas, lajes e cobogó. Pretende começar a produzir piso intertravado, pois está percebendo grande demanda de mercado. Suas fórmulas são feitas de cabeça, pela sua experiência, mas também pede ajuda a um engenheiro conhecido. O mesmo entende inovação como criar algo novo, reinventar algo já existente, criar novos processos, adquirir novos conhecimentos. Para ele tudo isso é importante para se mantiver competitivo no mercado. "Inovação é você mudar, botar o novo, reinventar, criar outra maneira de trabalhar, inovar em outros produtos. [...] Você tem que inovar, inovando em produtos, qualificação, conhecimento, isso é muito importante para acompanhar o desenvolvimento e as mudanças do mercado [...]" (Sujeito C, 2012).

Já a empresa D, localizada em Macaíba, é a única que se constitui como pequena empresa, com seu faturamento passando de $\mathrm{R} \$ 360.000,00$ e indo até $\mathrm{R} \$$ 3.600.000,00. Também é a única que possui setores definidos e investe em P\&D de novos produtos e aperfeiçoamento dos já existentes. $O$ foco desta empresa também é diferenciado, pois produz peças em grande escala de projetos arquitetônicos, caixa d'água, paredes pré-moldadas, etc. Além disso, tem o diferencial de ter equipe montadora, ou seja, não apenas fabrica, mas também constrói. Trabalha com grandes empresas. O empresário (Sujeito D) cursou Engenharia Náutica e já participou de diversos workshops e seminários sobre construção civil e peças pré-moldadas. $\mathrm{O}$ mesmo afirma que inovar é atender às necessidades dos clientes e lançar produtos que despertem a necessidade e curiosidade dos mesmos: "A inovação, no meu ponto de vista, é sempre atender à necessidade do cliente e ainda lançar um produto que desperte a curiosidade e a necessidade que até então ainda não havia despertado. [...] o povo tem essa necessidade de ver novas tendências" (Sujeito D, 2012).

\subsection{Análise das Dimensões do Radar da Inovação}

Antes de focar na dimensão Oferta, objeto deste estudo, é importante analisar como cada empresa se comportou em todas as dimensões do Radar da Inovação e sua pontuação total. Com isso, pode-se ter uma percepção mais ampla sobre o comportamento inovador de cada empresa do universo desta pesquisa.

Tabela 1: Grau de inovação do Radar da Inovação do universo investigado

\begin{tabular}{c|c|c|c|c}
\hline \multirow{2}{*}{ Dimensão } & \multicolumn{3}{c}{ Empresa / pontuação do radar da Inovação } \\
\cline { 3 - 5 } & $\mathbf{A}$ & $\mathbf{B}$ & $\mathbf{C}$ & $\mathbf{D}$ \\
\hline 1. Dimensão Oferta & 2,2 & 1,8 & 1,8 & 3,0 \\
\hline 2. Dimensão Plataforma & 3,0 & 3,0 & 2,0 & 4,0 \\
\hline 3. Dimensão Marca & 4,0 & 4,0 & 4,0 & 4,0 \\
\hline 4. Dimensão Clientes & 2,3 & 3,0 & 2,3 & 3,7 \\
\hline 5. Dimensão Soluções & 3,0 & 1,0 & 1,0 & 3,0 \\
\hline
\end{tabular}




\begin{tabular}{|c|c|c|c|c|}
\hline 6. Dimensão Relacionamento & 2,0 & 1,0 & 2,0 & 3,0 \\
\hline 7. Dimensão Agregação de Valor & 2,0 & 1,0 & 1,0 & 2,0 \\
\hline 8. Dimensão Processos & 1,7 & 2,0 & 1,7 & 2,3 \\
\hline 9. Dimensão Organização & 1,5 & 1,5 & 1,5 & 2,0 \\
\hline 10. Dimensão Cadeia de Fornecimento & 1,0 & 3,0 & 3,0 & 3,0 \\
\hline 11. Dimensão Presença & 1,0 & 1,0 & 1,0 & 2,0 \\
\hline 12. Dimensão Rede & 1,0 & 1,0 & 1,0 & 5,0 \\
\hline 13. Dimensão Ambiência inovadora & 1,8 & 1,5 & 1,8 & 2,0 \\
\hline Grau de Inovação Global & 2,2 & 2,0 & 2,0 & 3,2 \\
\hline
\end{tabular}

Fonte: dados coletados da Ferramenta Radar da Inovação, aplicado nas empresas em 2012.

De acordo com a tabela 1, pode-se observar que a diferença no grau de inovação global entre as quatro empresas analisadas é pequena, o único que se difere dos demais é a empresa $\mathrm{D}$, com pontuação de 3,2. A pontuação diferenciada é reflexo do perfil da empresa, que investe em $P \& D$, tendo em vista que segundo Pereira (2008), empresas que investem em P\&D se tornam mais competitivas e propensas a desenvolverem seus produtos e/ou serviços. De acordo com Bachmann e Destefani (2008), este também é um dos indicadores de inovação.

A segunda com maior grau é a empresa A, com pontuação de 2,2. Levando em consideração o perfil do empresário, que está sempre em busca de novidades e cursa Engenharia Civil, fica fácil perceber a correlação entre o Ensino Superior e a inovação. O que vem afirmar a premissa de Zago et al (2007), que afirmam que a busca por conhecimento e a troca de informações, seja ela feita através de parcerias, grupos empresariais ou em instituições de ensino, é fundamental para o processo de inovação.

Já as empresas B e C obtiveram a mesma pontuação no Grau de Inovação Global. Ao analisar o perfil das duas empresas e dos empresários, percebe-se semelhança entre elas que se refletem muito bem no radar. Ambos não formulam seus próprios produtos e dependem do conhecimento já adquirido por terceiros para aperfeiçoá-los, ficando assim muito mais difícil gerarem uma inovação radical.

\subsection{Análise da Dimensão Oferta: Uma Visão no Contexto da Inovação}

Após esta análise generalizada do radar como um todo, fica evidente a semelhança do Grau Geral de Inovação e da pontuação obtida apenas na dimensão analisada por este paper. No que se refere à pontuação obtida na dimensão Oferta, dentro do Radar da Inovação, assim como no Grau Geral, nenhuma das empresas analisadas obteve pontuação máxima de 5,0 (conforme pode ser observado no quadro 02). A empresa B e C obtiveram a mesma pontuação de 1,8 , a empresa $A$ obteve 2,2 e a D conseguiu o maior grau dentre as empresas pesquisadas: 3,0 . Isso 
demonstra o quanto há espaço para o desenvolvimento de ações que venham a tornar as empresas mais inovadoras.

Tabela 2: Grau de inovação da dimensão Oferta.

\begin{tabular}{c|c}
\hline Empresa & Pontuação \\
\hline A & 2,2 \\
\hline B & 1,8 \\
\hline C & 1,8 \\
\hline D & 3,0 \\
\hline
\end{tabular}

Fonte: Dados coletados da Ferramenta Radar da Inovação, aplicado nas empresas em 2012.

Com relação à primeira pergunta do radar (novos produtos), constatou-se que apenas a empresa D lançou com sucesso mais de um produto, nos últimos três anos. Esse dado não é surpresa, tendo em vista que esta empresa é a que obteve maior pontuação na dimensão Oferta e também é a empresa mais estruturada, com setores definidos e produção em grande escala. Outro fator que pode contribuir para esta pontuação é equipe técnica capacitada que a empresa possui, como poderá ser observado adiante, tendo em vista que segundo Bes e Kotler (2011) as empresas possuem grande potencial de inovação em suas fontes internas, ou seja, em seus colaboradores.

Com isso é possível analisar que inovação está correlacionada à capacidade de obter novas informações de mercado, ou seja, a busca constante por novidades, já que o Sujeito D citou que "Toda vez que tem workshop, e é possível, nós frequentamos, nós utilizamos essa metodologia" (Sujeito D, 2012). Esta afirmação é coerente com o conceito de que uma das formas de gerar inovação é através do estímulo, desenvolvimento e compartilhamento do conhecimento dentro das empresas (BES; KOTLER, 2011).

Também é possível perceber correlação direta com um dos fatores evidenciados pelo Sujeito B como um empecilho à inovação: a falta de capital para investimento. Talvez por a empresa D ser a com maior faturamento, ela também tenha mais capacidade de investir em novas tecnologias e novos produtos.

Já na segunda pergunta (ousadia), todas as empresas obtiveram respostas iguais: todos os produtos lançados no mercado, nos últimos três anos, tiveram sucesso. As empresas A, B e C só lançaram um novo produto com sucesso nos últimos três anos, ou seja, não tiveram muitas oportunidades para erro, ou seja, para lançamentos sem sucesso novos produtos. Já a empresa D, que lançou mais de um produto novo, nos últimos três anos, conseguiu ter sucesso em todos. Um dos possíveis fatores para isso pode ser, novamente, a utilização de corpo técnico especializado, tendo em vista que o empresário evidencia na entrevista que "[...] nós hoje estamos mais ousados, o nosso nível de conhecimento, de estudo e de pesquisa, ele já está um pouco mais amadurecido" (Sujeito D, 2012). 
Essa premissa está relacionada com a afirmação de Pereira (2008), a qual afirma que as empresas que investem em P\&D conseguem se tornar mais competitivas no mercado, desenvolvendo novos produtos e melhorando os processos de produção já existentes.

É importante salientar que tanto a questão "novos produtos" quanto "ousadia" são aqui classificadas como uma única variável: novos produtos.

$\mathrm{Na}$ terceira questão do radar, que aborda a variável sustentabilidade, apenas a empresa A mudou características de seus produtos por razões ambientais. Em parte, isso se dá pelo fato de o mesmo realizar estudo em sua faculdade, onde contempla o uso de novos materiais ecológicos.

Essa evidência traz novamente a questão abordada por Bes e Kloter (2011), que afirmam que para quebrar as barreiras da inovação é necessário estimular e desenvolver o conhecimento. A motivação para pesquisa sobre novos materiais ecológicos pode vir do esforço para tornar a indústria mais sustentável e ajudar a criar um mundo sem resíduos, onde tudo por ser reaproveitável ou pode simplesmente ter vindo da necessidade de reduzir custos e como consequência ser mais sustentável, como afirmam Sousa e Carvalho (2012).

Os Sujeitos B e C possuem pouco conhecimento sobre este tema, tendo em vista que não possuem formação acadêmica na área e nem realizam estudos de viabilidade, absorvendo apenas conhecimento de outros pré-moldados. Essa ignorância sobre o tema fica evidente na fala do Sujeito B: "Olhe, no pré-moldado até então eu sou assim, ignorante, eu não conheço alguma coisa nessa área. Já vi para outras coisas, como telhas [...] Mas outros produtos eu não conheço na área de pré-moldados" (2012).

Para os Sujeitos B e C produtos ecológicos estão, principalmente, relacionados a elementos como piso grama, piso intercravado poroso, meio fio (que é feito de concreto reciclado), entre outros. Em aspectos mais aprofundados de uso de novos insumos ou de processos construtivos feitos totalmente de estruturas pré-moldadas, eles não têm opinião formada, até porque seu foco é justamente nessas pequenas peças, já que eles não produzem produtos de maior escala, como a empresa D.

Para esses produtos, os sujeitos pesquisados acreditam ter aceitação de mercado, como pode ser observado na fala do empresário da empresa $\mathrm{C}$ quando questionado sobre se há demanda de mercado para estes materiais: “Tem. A conscientização hoje é direcionada justamente pra isso" (2012). Essa citação do empresário vem afirmar a $\mathrm{ABCP}$ quando esta ressalta que as estruturas pré-moldadas têm um papel fundamental para o caminho de construções sustentáveis e que a sociedade vem, a cada ano, adquirindo mais consciência sobre seu impacto ambiental.

No entanto, Pereira (2008) afirma que a construção civil enfrenta diversas barreiras para a inovação. Essa dificuldade do setor em inovar pode atrasar o avanço pela sustentabilidade, pois embora o conceito pré-moldado seja mais ecológico, ele 
ainda utiliza recursos não renováveis e seu ciclo não é totalmente fechado. Além disto, as atuais pesquisas para utilização de insumos naturais só se aplicam para pequenas estruturas.

Como pode ser observado na entrevista com o Sujeito $\mathrm{D}$, que afirma não utilizar insumos ecológicos, como o pó de brita, por exemplo, por não haver estudos suficientes em longo prazo que comprovem a eficácia dessas mudanças. No entanto, o mesmo afirma que o conceito de estruturas pré-moldadas já é por si um processo ecológico, tendo em vista que utiliza poucos recursos em sua produção e gera bem menos resíduos no ato da construção.

Essa premissa converge com a $\mathrm{ABCP}$, que afirma que estruturas pré-moldada se adequam às novas exigências sustentáveis, tendo em vista que o concreto não gera emissões, não requer conservantes tóxicos e consome menos energia na sua produção do que produtos similares da construção, como o tijolo, por exemplo.

Outro aspecto a ser salientado é o fato de Sujeitos A e D ressaltarem a resistência cultural da região Nordeste em aceitar novos produtos, mudando a forma como constroem suas edificações. Como cita o Sujeito D: "[...] nós ainda temos uma resistência a mudanças. Isso se chama cultural. Então a maior resistência das pessoas é a resistência cultural" (2012). Essa barreia ao encontro da afirmação de Bessant e Tidd (2009), onde a inovação depende da aceitação por parte da sociedade.

Outro ponto que deve ser observado é o fato de o empresário da empresa A ressaltar como um empecilho á inovação e á sustentabilidade a falta de apoio do governo. Para o mesmo: "[...] eu acho que tá faltando mais interesse, principalmente do governo [...] pra você inovar, pra você melhorar, pra economizar, pro meio ambiente, pra tudo, eu acho que tem que o próprio governo investir, porque quem vai investir num negocio que vai ajudar todo mundo e não vai ter retorno?" (2012). Ou seja, para ele, é necessário haver apoio do governo, seja reduzindo os impostos, com políticas de incentivo ou tendo linhas de crédito especializadas para projetos sustentáveis.

Nesse ponto, Sousa e Carvalho (2012) vêm atestar o ponto de vista do empresário, já que para os autores, desenvolvimento sustentável deve considerar aspectos como crescimento econômico, utilização adequada de recursos, e a empresa precisa ser financeiramente viável.

Com relação à quarta pergunta que aborda a variável design, novamente apenas a empresa D obteve resposta diferente das demais, afirmando ter realizado mudanças significativas na estética de seus produtos. Entra aqui mais uma vez a questão do corpo técnico capacitado, observando-se que, além do conhecimento científico, os colaboradores e o empresário dessa empresa participam constantemente de feiras e eventos do ramo para estarem sempre atentos às novidades do mercado. Pois, segundo o Sujeito D, as pessoas têm necessidade por novas tendências, por isso eles estão sempre em busca de novidades, novos produtos ou novos processos que 
venham atender às necessidades dos clientes, necessidades estas que antes nem eram conhecidas.

Este dado de a empresa D possuir corpo técnico capacitado e obter maior pontuação em inovação, tanto no Grau Geral do Radar quanto na dimensão objeto deste papper e nesta questão em si; vem confirmar uma das maiores dificuldades em inovar, que segundo Pereira (2008), é a falta de mão de obra qualificada. Com isso é possível perceber a importância de programas do governo brasileiro, como o Programa Nacional de Acesso ao Ensino Técnico e Emprego (Pronatec), por exemplo, que oferece cursos gratuitos a fim de capacitar os jovens para o mercado e produzir mão de obra especializada e qualificada.

Ao analisar a quarta variável do radar de inovação, que aborda melhoria de processos produtivos / inovação tecnológica, e última questão da dimensão Oferta, pode-se perceber que todas as empresas tiveram a mesma resposta. Isso demonstra que a inovação tecnológica ainda anda em passos lentos na região. Pode-se atribuir isso a vários fatores citados pelos próprios empresários entrevistados, como a falta de incentivos do governo, falta de capital para investimento e resistência cultural.

As respostas à variável mão de obra, que não se encontram no radar, mas que foram inseridas no roteiro de entrevistas, ajudaram a perceber como ela é importante na inovação de produtos. Isso porque, como já dito, as empresas possuem grande potencial de inovação em suas fontes internas (BES; KOTLER, 2011, p.17).

Essa fonte interna de inovação não tem restrição de setores, ela envolve toda a empresa. Entretanto, muitas vezes, ela se concentra na produção, como é o caso do setor estudado por este paper. O que vem confirmar um dos principais fatores para o lento desenvolvimento da inovação na construção civil, que segundo, Pereira (2008), é a mão-de-obra desqualificada. Entende-se, portanto que as quatro empresas entrevistadas afirmaram que ter mão-de-obra qualificada influencia sim no processo de produção.

Para o Sujeito A, a mão-de-obra qualificada é importante para garantir a qualidade do produto final. No entanto, ele sente dificuldade em encontrá-la no mercado e por isso prefere qualificá-los em sua empresa, tendo em vista que muitos só têm conhecimento empírico e possuem vícios de outras empresas, desrespeitando o empresário que possui conhecimento empírico e científico. O sujeito A destaca que é "[...] um risco muito grande se ela (a laje) for mal feita, ou seja, por mãos de pessoas que não sejam qualificadas" (2012). Esse risco vai além da qualidade, mas põem em riscos vidas, pois uma estrutura pré-moldada danificada pode levar ao desabamento de prédios e residências.

Já o Sujeito B acredita que a qualificação da mão-de-obra é essencial para o desenvolvimento seguro de seus produtos. No entanto, a qualificação que o mesmo se refere é a experiência de trabalho no ofício. Devido ao fato de em Natal não haver 
cursos especializados para qualificar quem trabalha com a elaboração do prémoldado, é importante considerar que qualificação, para este empresário, resume-se, aos longos anos, de experiência que o individuo possui.

Indo de acordo com o pensamento dos Sujeitos A e B, o Sujeito C também concorda que ter colaboradores experientes e qualificados "Ajuda na produção, interfere para a qualidade da produção. [...] Sai um custo maior, mas a qualidade, custo beneficio no final das contas sai melhor para a empresa" (Sujeito C, 2012). No entanto, este tem a percepção de qualificação semelhante ao Sujeito B, em que qualificação se traduz por experiência empírica.

Para o Sujeito D, ter mão-de-obra qualificada é indispensável para poder ter um produto final de boa qualidade. Nesse caso, diferente da empresa B e C, a qualificação que ele se refere vai além da experiência, tendo em vista que ele leva seus colaboradores para participarem de workshops. Além disso, tem engenheiros formados que elaboram todas as formulações de cada produto. Segundo ele, para ter um produto de qualidade e bem acabado "exige cuidado, exige atenção, exige pessoas capacitadas" (Sujeito D, 2012). Com estas premissas que os empresários possuem sobre a relação mão-de-obra e qualidade do produto, fica claro que todos reconhecem que possuir colaboradores qualificados (tanto empiricamente quanto teoricamente) aumenta a produtividade e qualidade final do produto.

No entanto, todos exprimiram sentir dificuldade em encontrar esta mão-deobra qualificada e isso é refletido em suas pontuações de inovação. Mesmo a empresa D obtendo o maior grau de inovação e possuindo corpo técnico capacitado, além de buscar constantemente por novos conhecimentos, esta ainda não atinge a pontuação 5 do radar. Deixando uma margem que poderia ser alcançada se houvesse mais qualificação no mercado.

Ao analisar a variável conhecimento científico, que também foi inserida no roteiro de entrevista, percebe-se como esse ponto ainda é pouco explorado pelos empresários, tendo em vista que apenas dois possuem formação acadêmica em engenharias. Além disto, quando questionados sobre possíveis parcerias entre suas empresas e instituições de Ensino Superior (IES), nenhum dos empresários entrevistados afirmou realizar qualquer tipo de parceria.

O Sujeito A afirma considerar o conhecimento científico e a parceria com IES fundamental para o desenvolvimento de novos produtos e para garantir o padrão de qualidade da empresa. No entanto, ele considera esta parceria limitada à construção do conhecimento científico que ele adquire na faculdade, não estendendo para projetos de viabilização de novos materiais, novos processos e outros aspectos que as IES possam vir a fazer com uma empresa privada, seja através de incentivos educacionais (bolsas de estudo), concursos ou propriedade intelectual. 
Para os Sujeitos B e C, é importante ter este conhecimento, seja para "[...] ficar a par de tudo o que ta acontecendo (na produção) [...]" (Sujeito B, 2012) ou para "[...] atender ao cliente, pra saber o que ele vai precisar" (Sujeito C, 2012). Embora eles não tenham formação acadêmica em engenharia, ambos afirmam que o conhecimento é importante para poder desenvolver produtos com qualidade, mesmo que seja só empírico e com a ajuda de terceiros.

No que diz respeito a parcerias com IES, ambos desconhecem as possibilidades que uma parceria entre IES pode oferecer. Eles não sabem como funciona e nem se tem custo. Conforme elucida o Sujeito B: "Isso aí eu não sei se tem um custo, [...] talvez pelo tamanho dessa empresa hoje, não sei se seria viável [...]" (Sujeito B, 2012). O Sujeito C acredita ainda que esta parceria se resume a "[...] estagiários [...] pegar o conhecimento, isso aí acho que ajuda bastante" (Sujeito C, 2012). Ou seja, ambos acreditam que parcerias deste tipo sejam para empresas grandes e estruturadas. Embora afirmem que se houvesse possibilidade seria interessante.

Em concordância com os demais, o Sujeito D acredita que ter conhecimento técnico é fundamental, tanto para se obter qualidade e segurança quanto para poder criar novos produtos. Segundo ele, a responsabilidade do fabricante de prémoldados é muito grande, desta forma, todo o conhecimento técnico auxilia para o cuidado da elaboração das formulações dos produtos. Com relação às parcerias, o mesmo afirma ser "Extremamente salutar [...] Ainda não viabilizamos, mas eu sempre tive isso em mente. É nas universidades que surge na verdade as grandes inovações [...]" (Sujeito D, 2012). Nesse caso, é o único que consegue enxergar o quão longe pode ir essa parceria e os benefícios que ela traz para a empresa, para as universidades e para o mercado como um todo.

Pode-se perceber com as respostas dadas pelos empresários que falta um elo entre IES e empresas. Na região da Grande Natal, ainda é grande a distância entre empresa privada e IES. Caso houvesse mais entrosamento, mais informações disponíveis, essas parcerias ocorreriam em maior quantidade, tendo em vista que todos os empresários entrevistados demonstraram interesse. E, no geral, o mercado como um todo sairia ganhando em mais qualidade e desenvolvimento.

\section{CONSIDERAÇÕES FINAIS}

O objetivo da pesquisa, que consistia em investigar, as práticas de inovação das micro e pequenas empresas do setor de estruturas pré-moldadas na região da Grande Natal, foi alcançado, pois foi possível perceber que as empresas, no universo estudado por este paper, ainda não desenvolveram uma cultura de inovação.

Para os empresários a inovação é importante, mas acaba sendo consequência da necessidade de mercado e não uma premissa de desenvolvimento. Desta forma, a 
maioria dos novos produtos de estruturas pré-moldadas acabam surgindo apenas pela necessidade do cliente, ou seja, pela demanda de mercado. Ao invés de haver pesquisa para lançamento de novos produtos que venham a oferecer melhor qualidade, durabilidade, sustentabilidade, etc, se antecipando a necessidade do cliente, como apenas uma das empresas entrevistadas faz.

Constatou-se também o importante papel da pesquisa e desenvolvimento e da busca constante por novos conhecimentos no processo de inovação. Quando uma empresa se acomoda e não procura por novas ideias, ela acaba ficando obsoleta. Não é necessário ter um setor de P\&D para desenvolver novos produtos, ele ajuda, mas só o fato do empresário buscar novidades e novos conhecimentos, seja em feiras, workshops, faculdades, entre outros, já é um grande passo para despertar a curiosidade, o interesse e por consequência, a inovação.

Outro ponto importante evidenciado na pesquisa é o fato de ainda não haver no estado do Rio Grande do Norte integração entre instituições de ensino superior e empresas no segmento em tela. Essa parceria é de grande relevância para se desenvolverem novos conceitos e novas tecnologias.

Com relação à sustentabilidade, foi possível extrair através desta pesquisa, que as empresas entrevistadas, e o setor nacional como um todo, ainda dão passos lentos nesse caminho. Parte disto é devido ao fato de as pesquisas neste campo ainda serem poucas.

No entanto é importante lembrar que as estruturas pré-moldadas em si já são uma opção mais ecológica que a construção convencional. Outra parte disto se dá pelo fator cultural, a resistência da população em aceitar estes novos materiais e as novas formas de construção. A falta de conhecimento por parte da população sobre o assunto é um dos entraves. Seria interessante o governo se envolver mais com o assunto, apoiando instituições de pesquisa para desenvolvimento de novos produtos e novos materiais e também oferecendo informação aos consumidores. Planos de incentivos fiscais para quem aderir a estes materiais, seja empresa ou pessoa física, é outro ponto que o governo e os bancos deveriam trabalhar mais.

Através da pesquisa também é possível compreender que os empresários de micro e pequenas empresas, dificilmente, executam tudo o que o radar pontua como uma empresa muito inovadora. Geralmente, a pontuação geral fica em média de 2,3, o que significa que não são empresas muito inovadoras, mas que também não são empresas estagnadas.

Isso demonstra que ainda há um campo aberto de inovação para ser trabalhado junto a estas empresas. O primeiro passo já foi dado por todas elas, tendo em vista que todos os empresários entrevistados possuem um conceito coerente sobre inovação, sem se restringirem apenas a novos produtos, mas também a aperfeiçoamento de produtos já existentes e melhorias de processos produtivos. 
CAPELEIRO, M. C. C.; ARAÚJO, R. M. de. Análise sobre a Dimensão Oferta...

Dessa forma, fica mais fácil incentivar a cultura da inovação, ou seja, a inovação como filosofia e não apenas para suprir necessidades.

É importante ressaltar que os resultados deste paper estão limitados quanto ao número de empresas e à região analisada, não devendo ser generalizado. A fim de se obter dados mais conclusivos e que representem uma discussão mais ampla e mais fiel às realidades das empresas de estruturas pré-moldadas norte rio-grandenses, recomenda-se uma pesquisa quantitativa que inclua outras regiões do estado, numa perspectiva comparada. Dentre as limitações identificadas no campo, destaca-se o acesso à agenda dos sujeitos para a realização das entrevistas.

\section{REFERÊNCIAS}

AAKER, David A, KUMAR, V., DAY, George S. Pesquisa de Marketing. São Paulo: Atlas, 2010.

ALMEIDA, Antônio Rafael Barbosa de. Pequenos Negócios: desafios e perspectivas. Brasília: Sebrae, 2012.

Associação Brasileira de Cimento Proteland - ABCP. Disponível em: <www.abcp.org.br>. Acessado em setembro de 2012.

BACHMANN, Dórian L. e DESTEFANI, Jully Heverly. Metodologia para Estimar o Grau de Inovação nas MPE - Cultura do Empreendedorismo e Inovação. Curitiba, 2008.

BACHMANN, Dórian . Metodologia para determinar o radar da inovação nas pequenas empresas. Curitiba: [s.n.], 2011. (Material de treinamento).

BERGO, César Augusto Moreira. Conceitos Básicos De Economia. Anbima, 2011.

BES, Fernando Trías de, KOTLER, Philip. A Bíblia da Inovação: princípios fundamentais para levar a cultura da inovação contínua às organizações. São Paulo: Lua de Papel, 2011.

BESSANT, John, TIDD, Joe. Inovação e Empreendedorismo. Porto Alegre: Bookman, 2009.

Câmara Brasileira da Indústria da Construção - CBIC. Disponível em: www.cbic.org.br. Acessado em setembro de 2012. 
DINIZ, Clélio Cammpolina, $\mathbf{O}$ papel das inovações e das instituições no desenvolvimento local. In: XXIX ENCONTRO NACIONAL DE ECONOMIA. 2011, Salvador. Anais ANPEC - Associação Nacional dos Centros de Pós-graduação em Economia, 2011.

DORNELAS, José Carlos Assis. Empreendedorismo: transformando ideias em negócios. Rio de Janeiro: Elsevier, 2008.

IGLESIA, Tiago Borges. Sistemas construtivos em concreto pré-moldado.Trabalho de conclusão de Curso pela Universidade Anhembi Morumbi. São Paulo, 2006.

NETO, Pedro L. C. Formas de Amostragem - Estatística. Blucher Ltda, 1977

PAIVA, Carlos Águedo Nagel, CUNHA, André Moreira Cunha. Noções de economia. Brasília: Fundação Alexandre Gusmão, 2008.

PEREIRA, Nicole de Castro. Análise das condições político institucionais para Inovação Tecnológica na Construção Civil: adobe produzido com macrofilas aquáticas em Palmas - TO. Trabalho de conclusão de Curso pela Universidade de Brasília, Brasília, 2008.

SANTOS, Carlos Alberto dos (org). Pequenos Negócios: desafios e perspectivas. Brasília: Sebrae, 2012.

SOUSA, Laura Teixeira de, CARVALHO, Luciana. Inovação de processo $\boldsymbol{e}$ sustentabilidade na prestação de serviço: um estudo sobre o caso Unhas Fast in Pequenos Negócios: desafios e perspectivas. Org. SANTOS, Carlos Alberto dos. Brasília: Sebrae, 2012.

TERRA, José Cláudio Cyrineu (org). Inovação: quebrando paradigmas para vencer. São Paulo: Saraiva, 2007.

TURETTA, André Luiz. Inovação em processos produtivos potencializa sustentabilidade em pequenas confecções no Paraná in Pequenos Negócios: desafios e perspectivas. Org. SANTOS, Carlos Alberto dos. Brasília: Sebrae, 2012.

ZAGO, Camila Avozani; CAMFIEL, Cláudio Eduardo Ramos; POLACINSKI, Édio; GODOY, Leoni Pentiado; WITTMANN, Milton Luiz. RAI. Redes associativas como 
CAPELEIRO, M. C. C.; ARAÚJO, R. M. de. Análise sobre a Dimensão Oferta... inovação organizacional: estudo de caso de uma rede supermercadista. Revista de Administração e Inovação, São Paulo, v. 4, n.1, p. 57-70, 2007. 


\section{APÊNDICE}

Quadro 01: Roteiro de Entrevista

1- Qual o seu conceito sobre inovação e qual sua percepção sobre a importância de inovar para se manter competitivo?

2- Em seu ponto de vista, até que ponto o conhecimento teórico interfere no desenvolvimento de novos produtos?

3- Quais os fatores que o senhor identifica como empecilho na busca de novos produtos (lançamento ou desenvolvimento) e novos insumos?

4- Quais os meios que o senhor utiliza para acompanhar as tendências de mercado?

5- Em sua percepção, até que ponto é interessante para a empresa, fechar parcerias com instituições de ensino superior (cursos de engenharia, produção, etc) a fim de absorver conhecimentos e tecnologias que venham a desenvolver novos ou aperfeiçoar os produtos já existentes?

6- Para o senhor, ate que ponto a utilização/não utilização de mão de obra qualificada interfere na qualidade do produto e geração de novas propostas?

7- Como o senhor enxerga o uso de materiais mais ecológicos em seus produtos? Acredita que há demanda no mercado?

Fonte: elaborado pela autora, 2012

Quadro 2: Radar da inovação, perguntas da dimensão Oferta

\section{A - Dimensão Oferta}

\section{Item 2 - Novos produtos}

A empresa lançou, com sucesso, mais de um novo produto no mercado nos últimos 3 anos.

A empresa lançou, com sucesso, um novo produto no mercado nos últimos 3 anos.

A empresa não lançou, com sucesso, qualquer novo produto no mercado nos últimos 3 anos.

\section{Item 3 - Ousadia}

Nos últimos 3 anos, a empresa retirou do mercado mais de um produto que não teve sucesso.

Nos últimos 3 anos, a empresa retirou do mercado um produto que não teve sucesso.

Nos últimos 3 anos, todos os produtos colocados no mercado tiveram sucesso.

Item 4 - Resposta ao meio ambiente

A empresa mudou características de mais de um produto por razões ambientais (ecológicas).

A empresa mudou alguma característica de um de seus produtos por razões ambientais (ecológicas).

A empresa não mudou qualquer característica de seus produtos por razões ambientais (ecológicas).

\section{Item 5 - Design}

Nos últimos 3 anos, a empresa fez mudanças significativas na estética, desenho ou outra mudança subjetiva em mais de um dos produtos.

Nos últimos 3 anos, a empresa fez alguma mudança significativa na estética, desenho ou outra mudança subjetiva em pelo menos um dos produtos. 
CAPELEIRO, M. C. C.; ARAÚJO, R. M. de. Análise sobre a Dimensão Oferta...

Nos últimos 3 anos, a empresa não fez qualquer mudança significativa na estética, desenho ou outra mudança subjetiva em nenhum produto.

Item 6 - Inovações Tecnológicas

Nos últimos 3 anos, a empresa adotou mais de uma das seguintes inovações de produto:

- uso de novos materiais

- uso de novas peças funcionais

- uso de tecnologia radicalmente nova.

Nos últimos 3 anos, a empresa adotou pelo menos uma das seguintes inovações de

produto:

- uso de novos materiais

- uso de novas peças funcionais

- uso de tecnologia radicalmente nova.

Nos últimos 3 anos, a empresa não adotou pelo menos uma das seguintes inovações de produto:

- uso de novos materiais

- uso de novas peças funcionais

- uso de tecnologia radicalmente nova.

Fonte: SEBRAE, 2012 